\title{
Produção familiar e formas de permanência no campo - Distrito de Cruzeiro do Norte - Uraí - PR
}

\author{
Familia de producción y formas de estancia en el campo - \\ Distrito Norte de Crucero - Uraí - Pr
}

\author{
Family production and ways of remaining in the field - Cruzeiro \\ do Norte District, Uraí - PR
}

\author{
Cleuza Batista de Oliveira \\ cleuza@seed.pr.gov.br \\ Universidade Estadual De Londrina
}

\begin{abstract}
Resumo: Este artigo é o resultado da dissertação de Mestrado, em Geografia pela Universidade Estadual de Londrina. Tem como objeto de estudo agricultores que se caracterizam por deter os meios de produção ao mesmo tempo em que trabalham na propriedade rural. São os chamados "agricultores familiares". Estudou-se um caso específico, os agricultores do distrito de Cruzeiro do Norte, localizado no município de Uraí - PR, norte do Paraná, com o objetivo de analisar se a forma de comercialização desenvolvida por esses agricultores agrega maior valor ao produto final, e se esse fator está substancialmente fortalecendo o desenvolvimento da agricultura familiar no distrito. A pesquisa nessa perspectiva foi delimitada de acordo com aspectos relacionados com as estratégias de adaptação e reprodução da agricultura familiar sob o modo capitalista de produção. A partir dos dados coletados na pesquisa empírica foi possível obter um perfil mais completo desses agricultores familiares no que diz respeito aos elementos da produção familiar, e constatar também que a forma de comercialização diferenciada parece se inserir nessas propriedades e se tornou uma alternativa viável para a geração de renda familiar e principalmente para manter o agricultor familiar no campo.
\end{abstract}

Palavras-chave: Agricultura familiar. propriedade da terra. produção e diversificação.

Resumen: Este artículo es el resultado de la Tesis de Maestría en Geografía de la Universidad Estatal de Londrina. Tiene como objeto de estudio, que se caracterizan por los agricultores tienen los medios de producción, mientras trabajaba en la granja. ¿Son los "agricultores familiares". Estudiado el caso concreto, los agricultores del Distrito de Crucero del Norte, ubicada en el municipio de Uraí - PR, el norte de Paraná, con el objetivo de analizar la forma de comercialización desarrollada por estos agricultores, añade mayor valor al producto final, y si este factor está reforzando considerablemente el desarrollo de la agricultura familiar en el Distrito. La investigación en esta perspectiva se define de acuerdo con los aspectos de las estrategias de adaptación y la agricultura familiar en el marco del modo de producción capitalista. A partir de los datos recogidos en la investigación empírica fue posible obtener un perfil más completo de estos agricultores en relación con los elementos de la producción familiar, y tener en cuenta que la forma de comercialización diferenciada parece insertar 
aquellas propiedades donde se ha convertido en una alternativa viable a la generación de ingresos y principalmente para mantener la agricultura familiar en el campo.

Palabras clave: Granja de la familia. la propiedad de la tierra. la producción y la diversificación.

\begin{abstract}
This article is the result of a Master's Thesis in Geography, State University of Londrina. It has as study objects farmers, characterized by haveing the means of production while working on the farm, "family farmers". We studied a specific case, the farmers of the District of Cruzeiro do Norte, located in the city of Uraí - Paraná, north of state, with the aim of analyzing if the form of marketing developed by these farmers, adds greater value to the final product, and if this factor is substantially strengthening the development of family farming in the district. The research, in this perspective, was defined according to aspects of the strategies of adaptation and reproduction of family farming under the capitalist mode of production. From the data collected in empirical research, it has been possible to obtain a more complete profile of farmers with regard to the elements of family production, and also noted that the differentiated form of marketing seems to enter those properties where it has become a viable alternative
\end{abstract}

Keywords: Family agriculture. land ownership. production and diversification.

\title{
INTRODUÇÃO
}

Os fundamentos teóricos desta pesquisa pautam-se na revisão de literatura sobre o modo capitalista de produção na agricultura familiar, os elementos dessa produção, a diversificação, bem como as estratégias de comercialização. Apesar da falta de políticas públicas a seu favor, a agricultura familiar vem demonstrando ser mais eficiente do que a agricultura patronal. Portanto, em certas áreas esse tipo de agricultura permaneceu e encontrou diversas formas para se reproduzir. Foi verificada no distrito de Cruzeiro do Norte em Urai - PR a persistência desse tipo de agricultura e a resistência de agricultores na terra.

Martins (1983), em um estudo sobre as relações capitalistas e a expansão do capitalismo no campo, faz um alerta com relação a abordagens que muitas vezes são equivocadas, quando o assunto não é tratado com a devida seriedade, pois a expressão "expansão do capitalismo no campo" tem sido usada como

[...] uma espécie de conceito mágico que explicaria tudo - seja para o economista, seja para o sociólogo, o antropólogo, o missionário, o militante político, o agente de pastoral, o homem comum. Explicaria até mesmo fatos opostos entre si, como a preservação do chamado campesinato e a expropriação desse mesmo campesinato. Se os camponeses não são expulsos da terra, isso é por causa da expansão do capitalismo, se são expulsos também é por causa da expansão do capitalismo. (MARTINS, 1981, p.151).

Na sua concepção, quando falam na expansão do capitalismo no campo, as pessoas querem se referir a duas coisas, pelo menos, combinadas entre si. 
[...] de um lado, uma massa crescente de camponeses, isto é, de lavradores autônomos cuja existência está baseada estritamente no seu trabalho e no de sua família, estaria sendo expulsa da terra, expropriada: de outro lado, em conseqüência, essa massa de lavradores estaria se transformando em massa de proletários rurais, de trabalhadores sem terra. O principal da expansão do capitalismo é basicamente isso (MARTINS, 1981, p.151).

Conforme colocações do autor há significados e divergências distintas, dependendo da ótica de abordagem dos autores. Com sábias observações Martins (1983) analisa que a questão é complexa e necessita de conceitos e referências bem fundamentados sobre o desenvolvimento agrário no modo de produção capitalista. Nesse sentido, vale lembrar as palavras de Oliveira (1995, p.6), que discute a permanência ou a extinção dessas unidades de produção familiar. "É a força de trabalho familiar que tem um papel muito significativo e vem aumentando numericamente de modo expressivo". O autor ainda afirma que o desenvolvimento capitalista se faz movido por suas contradições:

Para uns, ele leva inevitavelmente à homogeneização [...] para outros, esse processo é contraditório, portanto heterogêneo, o que leva a criar obviamente, no processo de expansão do assalariamento no campo, o trabalho familiar. (OLIVEIRA, 1995,p.6).

Esse desenvolvimento contraditório segundo o mesmo autor "ocorre através de formas articuladas pelos próprios capitalistas que se utilizam dessas relações de trabalho para não terem que investir na contratação de mão de obra uma parte de seu capital" (OLIVEIRA, 1991, p.19). Esse nada mais é do que o processo de produção do capital, como explica Oliveira (1991, p.18-19), que se faz através de relações não capitalistas. Nessa trajetória, segundo o autor, ao mesmo tempo que utilizam dessa relação sem remunerá-la, os capitalistas recebem uma parte do fruto do trabalho desses trabalhadores, [...] convertendo-se em mercadoria, transformando-a em capital.

Oliveira (1991) aborda a questão das contradições do desenvolvimento capitalista na agricultura em sua obra A Agricultura Camponesa no Brasil em que revela que "[...] o próprio capital pode lançar mão de relações de trabalho e de produção não capitalistas (parceria, familiar) para produzir o capital". Complementando seu pensamento, Oliveira (1991, p.20) observa que isso foi possível através da transferência da renda da terra em produto, quando da parceria, ou em dinheiro, quando o pagamento é feito em dinheiro, e/ou em trabalho, pelos camponeses, parceiros ou rendeiros [...].

O processo do desenvolvimento do capitalismo está intimamente relacionado ao processo contraditório de reprodução ampliada do capital, ou seja, conforme Oliveira (1991), o modo capitalista de produção não está circunscrito apenas à produção imediata, mas também à circulação de mercadorias; portanto, inclui também a troca de mercadorias por dinheiro e, obviamente, de dinheiro por mercadorias.

Oliveira (1991, p.18) entende também que o chamado processo econômico é constituído de quatro momentos distintos, porém articulados, unidos contraditoriamente. Esses momentos são o da produção imediata, da distribuição, da circulação e do consumo. Assim, o desenvolvimento do modo capitalista de produção, entendido como processo 
contraditório de reprodução ampliada do capital, pressupõe a criação capitalista de relações não-capitalistas de produção, uma vez que o capital, ao se reproduzir, reproduz também de forma ampliada as suas contradições (OLIVEIRA, 1991, p.29).

Retomando algumas discussões sobre a importância do termo "agricultura familiar", pode-se observar que ele já está sendo reconhecido como uma maneira de qualificar as formas de organização de unidades produtivas, politicamente correspondente ao desejado valor econômico-social emergindo assim no decorrer desses processos, a construção do "agricultor familiar" como sujeito de direitos, consagrados pelo Programa Nacional de Fortalecimento da Agricultura Familiar - Pronaf (Decreto no 1946, de 28 de junho de 1996; Resolução 2310, de 29 de agosto de 1996). (NEVES, 2007).

Assim, resumindo,

[...] o termo agricultura familiar corresponde então à convergência de esforços de certos intelectuais, políticos e sindicalistas articulados pelos dirigentes da Confederação Nacional dos Trabalhadores na Agricultura, mediante apoio de instituições internacionais, mais especialmente a Organização das Nações Unidas para Agricultura e Alimentação (FAO) e o Banco Internacional de Reconstrução e Desenvolvimento (BIRD). (NEVES, 2007, p. 230).

A autora, em sua argumentação sobre a categoria "agricultura familiar", afirma que o termo hoje utilizado em textos acadêmicos aparece sob a pretensão de conceito. Sob esse ponto de vista, define-se agricultura familiar como uma forma de organização e gestão das relações de produção e trabalho, cujo eixo fundamental está referenciado à dinâmica da constituição da família (LAMARCHE apud NEVES, 2007). Para efeito de uma definição, a agricultura familiar corresponde a formas de organização da produção em que a família é ao mesmo tempo proprietária dos meios de produção e executora das atividades produtivas. Essa condição imprime especificidades à forma de gestão do estabelecimento.

Segundo estudos realizados por professores de economia da UNICAMP, Buainain, Romeiro e Guanziroli, (2003), no dossiê apresentado sobre a agricultura familiar e o novo mundo rural, os autores relatam que a agricultura familiar é um universo profundamente heterogêneo, seja em termos de disponibilidade de recursos, acesso ao mercado, capacidade de geração de renda ou acumulação. Essa diversidade é também regional. Por outro lado, esses estudos mostram que a agricultura familiar explora de forma intensiva os recursos escassos disponíveis e que é possível gerar níveis de renda agropecuária superior ao nível de reprodução da família. Naturalmente que nem sempre este potencial se realiza, seja em razão de severas restrições de recursos enfrentados pelos agricultores familiares particularmente na Região Nordeste, seja por causa das condições macroeconômicas negativas e da ausência/deficiências das políticas públicas que deveriam, pelo menos, contrabalançar, os efeitos negativos das políticas e da conjuntura macroeconômica. (BUAINAIN, ROMEIRO E GUANZIROLI, 2003, p.327b).

Refletindo sobre o que foi exposto pelos autores o segmento de produtores rurais familiares foi duramente atingido pelas políticas de modernização da indústria e principalmente pela insuficiência de políticas públicas voltadas para subsidiar a produção 
familiar, em particular os programas de crédito específicos para esse setor. Alguns sistemas enfrentam ainda problemas de mão de obra. Quanto a essa restrição os autores associam quatro fatores: intensificação do uso do fator trabalho à medida que os sistemas se tornam mais complexos e integrados aos mercados agroindustriais; tamanho da família e da mão de obra familiar disponível; tecnologia inadequada para as necessidades da agricultura familiar e/ou inviável economicamente; falhas no mercado de trabalho local. (BUAINAIN, ROMEIRO E GUANZIROLI, 2003, p. 331).

Embora a escassez de mão de obra seja parcialmente compensada economicamente pela elevação da produtividade e pela utilização de mão de obra assalariada temporária, isso exige maior investimento além de reduzir as vantagens próprias da produção familiar. De modo geral os agricultores familiares enfrentam a concorrência de grandes produtores que se beneficiam de subsídios e acesso privilegiado aos serviços de comercialização. Nas atividades exploratórias de campo foram identificados além dos problemas, potencialidades na prática da agricultura familiar. Os problemas e potencialidades da agricultura familiar já foram apontados em estudos anteriores, dos quais julgamos importante trazer referências.

Assim, a maioria das definições de agricultura familiar adotadas em trabalhos recentes sobre o tema, baseia-se na mão de obra utilizada, no tamanho da propriedade, na administração dos trabalhos e na renda gerada pela atividade agrícola. Em todas há um ponto em comum: ao mesmo tempo que é proprietária dos meios de produção, a família assume o trabalho no estabelecimento.

Este trabalho investigou, na área de estudo, a mão de obra utilizada, tamanho das propriedades e a diversificação da produção como estratégia de reduzir riscos. Portanto, esta pesquisa tem como objeto de estudo, agricultores que se caracterizam por deter os meios de produção, a propriedade privada da terra por meio da força de trabalho familiar.

\section{MATERIAIS E MÉTODOS}

Para o estudo foi escolhida uma comunidade rural, mais especificamente o distrito de Cruzeiro do Norte, localizado no município de Uraí, norte do estado do Paraná. Uma das justificativas na escolha do distrito de Cruzeiro do Norte está relacionada às leituras realizadas anteriormente e que indicaram algumas especificidades locais, como, por exemplo, a gênese dessa comunidade, ligada aos paulistas e nordestinos cuja situação foi diferente da maioria dos japoneses, que se fixaram no município de Uraí e em terras melhores que do distrito de Cruzeiro do Norte. Uma das curiosidades científicas foi despertada pelo fato de ser uma comunidade não étnica, encravada e colonizada por empreendedores étnicos, no caso, os japoneses. A escolha do distrito de Cruzeiro do Norte prende-se então ao fato de ser uma "comunidade" que majoritariamente é composta por brasileiros não descendentes de japoneses e tem como atividade principal a agricultura, mais especificamente a viticultura de mesa, embora a diversificação da produção tenha sido uma das estratégias de permanência no campo. 
Apesar de a agricultura familiar ter assumido grande importância dentro do modo de produção capitalista (produção de alimentos para abastecer a população na cidade, geração de emprego e renda, manutenção das pessoas ocupadas no campo), ela ainda padece com uma série de fatores: falta de políticas agrárias e agrícolas, baixo valor agregado dos seus produtos, expropriação e envelhecimento da família rural, perda de lavouras diante das oscilações climáticas, dificuldades de comercializar em razão da concorrência desleal, a entrada de produtos industrializados no mercado e do acúmulo de dívidas, o que levou muitos produtores à ruína.

Assim, o tema escolhido se situa no âmbito da agricultura familiar, uma vez que essa categoria de produtor tem sido tratada, a partir do governo Fernando Henrique Cardoso, com determinadas políticas agrícolas, tais como o Programa Nacional de Fortalecimento da Agricultura Familiar (PRONAF), dentre outros programas não menos relevantes. Por outro lado, tem-se observado que cada vez mais está ocorrendo o abandono do campo por essa categoria de produtores o que direcionou esse estudo para a compreensão das formas encontradas pelos produtores do distrito de Cruzeiro do Norte para superar os problemas atinentes ao campo brasileiro, tornando viável a agricultura familiar no processo de desenvolvimento capitalista.

Diante disso faz-se necessário analisar se a diversificação da produção nas unidades produtivas familiares influenciou diretamente as condições de permanência de agricultores familiares no campo, se a forma de comercialização desenvolvida por uma grande parcela desses agricultores está agregando maior valor ao produto final, e se esse fator está substancialmente fortalecendo o desenvolvimento da agricultura familiar no Distrito. A diversidade dessa forma social de produzir na agricultura demonstra a capacidade de adaptação e reprodução desses agricultores numa tentativa de permanecer no campo, vivendo com a renda da terra.

As entrevistas iniciais de campo demonstraram que apesar das transformações ocorridas na agricultura, o pequeno agricultor ainda quer se manter na propriedade. Uma das alegações é a afirmação de que é "só isso que ele sabe fazer", mas, quando se trata da permanência dos filhos no campo, ele reluta em dizer que os mesmos têm outras oportunidades e perspectivas e devem buscar outra atividade no mercado de trabalho.

Analisando sob esse ponto de vista, e no atual contexto em que se inserem esses agricultores familiares na reprodução social, optou-se por entrevistas na tentativa de compreender a diversidade que ora se apresenta nesse segmento e suas relações sociais de produção. Inicialmente foi realizada uma revisão bibliográfica dos grandes temas vinculados à agricultura de um modo geral, verificando-se alguns assuntos específicos nos seguintes campos: 1 - Geografia Agrária, particularmente os assuntos relacionados ao desenvolvimento capitalista, aprofundando-se as seguintes questões: referências e conceitos sobre a agricultura familiar para dar suporte teórico-metodológico ao desenvolvimento da pesquisa. Muitos trabalhos empíricos pesquisados foram de fundamental importância para compreender os problemas e as características do assunto pesquisado. Assuntos correlatos à agricultura familiar, como perfil da família, nível socioeconômico, características da produção, formas de comercialização, relações de trabalho, dificuldades na sua prática 
agrícola, formas e conflitos sobre a resistência em permanecer no campo, problemas de continuidade da atividade; 2 - Sociologia Rural: nessa subdisciplina muitas questões teóricas têm sido discutidas, com várias matrizes principalmente europeias, que foram úteis para compreender o processo de desenvolvimento do capitalismo no campo, ao lado de geógrafos consultados. 3 - Antropologia Rural: os antropólogos têm realizado uma série de estudos com temática rural, principalmente com relação à constituição da família e o papel da comunidade como referência fundamental na compreensão dos aspectos socioeconômicos de pequenas comunidades rurais, como é o caso do distrito de Cruzeiro do Norte, nosso estudo de caso. 4 - Agronomia: no campo da Agronomia, atualmente muitos trabalhos técnicos e empíricos têm apresentado um bom suporte teórico, principalmente no que se refere à produção e à comercialização dos produtos agrícolas.

Após a revisão bibliográfica realizada, sistematizamos as leituras, fazendo uma análise crítica e filtrando referências teóricas e metodológicas utilizadas nessa pesquisa. O levantamento empírico foi precedido de uma atividade exploratória em que foram percorridas as propriedades rurais do distrito de Cruzeiro do Norte, com o objetivo de fazer um levantamento preliminar de informações concernentes à região como um todo, especificamente sobre a formação histórica e as características socioeconômicas predominantes, que permitiram elaborar o instrumento de pesquisa, em razão das trocas de ideias com os moradores. Outras fontes forneceram subsídios, entre elas a Prefeitura Municipal de Uraí e o Instituto Paranaense de Assistência Técnica e Extensão Rural - (Emater).

Após essas atividades exploratórias foi elaborado o instrumento de coleta de dados, composto de entrevistas e questões objetivas. As linhas gerais do levantamento de campo estão estruturadas da seguinte forma: características do proprietário ou do administrador; perfil da família; ocupação da terra; relações de trabalho comercialização. Esse levantamento foi realizado por meio de perguntas bem abertas, mais características de uma entrevista informal. Outra importante fonte de dados foram as publicações do Instituto Brasileiro de Geografia e Estatística - (IBGE), principalmente os censos demográficos e agropecuários do estado do Paraná, por meio dos quais foi possível resgatar dados desde 1970, o início do recorte temporal da pesquisa.

Após a coleta de dados no campo, as informações foram sistematizadas em tabulações e confecções de figuras e representações gráficas e mapeamentos, e em seguida foi feita uma análise crítica dos dados levantados. Entre os vários caminhos metodológicos, a pesquisa qualitativa referente ao levantamento realizado no campo foi um dos mais profícuos na compreensão do significado rural e socioeconômico do distrito de Cruzeiro do Norte. As entrevistas iniciais demonstraram que, o pequeno agricultor ainda quer se manter na propriedade. Uma das alegações é a afirmação de que é "só isso que ele sabe fazer"' mas, quando se trata da permanência dos filhos no campo, ele reluta em dizer que os mesmos têm outras oportunidades e perspectivas e devem buscar outra atividade no mercado de trabalho. 


\section{RESULTADOS E DISCUSSÃO}

Segundo o levantamento feito em campo, os produtores familiares do distrito de Cruzeiro do Norte utilizam de forma intensiva a força de trabalho familiar. As unidades produtivas que foram analisadas demonstram que a participação direta da mão de obra familiar é presente em 100\% do pessoal ocupado nos estabelecimentos. Observou-se também que 50\% da mão de obra utilizada nas unidades de produção familiar é formada por temporários advindos do distrito de Cruzeiro do Norte. Essa situação justifica-se pela atividade predominante desenvolvida - a viticultura.

Os resultados da pesquisa de campo demonstraram que é característica marcante da área de estudo as propriedades com classe de área total que variam de 2 a 30 hectares. Das 30 famílias pesquisadas, correspondendo a uma área de aproximadamente 428,77 hectares, $100 \%$ cultivam a uva como principal atividade produtiva da família. Os grupos familiares produtores de uva na área de estudo apresentam características semelhantes às referenciadas por Lamarche (1993), que define a agricultura familiar como aquela em que o trabalho, a terra, o capital e a gestão da propriedade são predominantemente familiares. $\mathrm{O}$ agricultor que possui um pedaço de terra e nele produz com seu próprio trabalho e de sua família, e com capital proveniente desse trabalho, é caracterizado como familiar.

Assim, a reprodução das famílias pesquisadas só é possível porque a lógica desses produtores é a permanência na propriedade através do trabalho familiar, e para isso há a constante busca por estratégias para não serem expropriados.

\section{CONSIDERAÇÕES FINAIS}

Não se pode negar a recorrência com que hoje, em textos acadêmicos, a categoria agricultura familiar é utilizada sob a pretensão de conceito. Nesses casos e sob essa linha de pensamento, ela é definida como uma forma, entre tantas outras, de organização e gestão das relações de produção e trabalho, cujo eixo fundamental está referenciado à dinâmica da constituição da família (Lamarche, 1993). Para Tavares dos Santos (1984), a especificidade desse processo de trabalho provém, inicialmente, da presença da força de trabalho familiar configurada como um trabalhador coletivo, que provoca eventualmente a utilização da força de trabalho assalariada na unidade produtiva. Aliada a esses fatores a prevalência da produção familiar na área de estudo é explicada pelas estratégias produtivas adotadas por esses trabalhadores, especificamente um sistema de produção diversificado.

O presente trabalho teve como objetivo analisar se as práticas agrícolas dos agricultores familiares do distrito de Cruzeiro do Norte contribuíram para sua permanência no campo. Para alcançar esse objetivo optou-se por entender as abordagens teóricas realizando leituras pertinentes ao tema. A análise precedente dos dados demonstrou que os agricultores familiares da área de estudo identificam as oportunidades e utilizam de forma intensiva os recursos disponíveis. Constatou-se também, que na maioria dos casos as 
dificuldades enfrentadas devem-se a fatores externos, e não se prendem especificamente ao fato de serem "pequenos produtores", termo amplamente utilizado para justificar muitas vezes a inviabilidade da produção familiar.

A diversidade de situações nas quais se encontra a agricultura familiar se reflete nos diferentes sistemas e estratégias de produção adotados pelos agricultores familiares. Uma alternativa característica da área de estudo para a permanência no campo são as estratégias produtivas criadas pelos produtores. Os resultados da pesquisa exemplificaram a capacidade de adaptação dos agricultores familiares do distrito de Cruzeiro do Norte, que se mantêm com a renda da terra buscando novos produtos aliados à diversificação da produção. De acordo com as informações obtidas no trabalho de campo, quanto maior a diversificação do sistema produtivo, menores os riscos corridos pelos produtores e maior a renda auferida. Essa é uma das principais características presentes na pesquisa realizada.

A diversificação da produção foi observada em todas as propriedades familiares pesquisadas. Os produtores adotam em geral sistemas produtivos que envolvam basicamente a mão de obra familiar, utilizando, quando necessário mão de obra temporária. Nessa situação garantem que a estratégia é gerar a maior renda possível por hectare produzido. Trata-se, assim, do aproveitamento que o proprietário faz da área total disponível, e nesse caso específico da área de estudo, constatou-se que os produtores do distrito aproveitam ao máximo sua área total. Observou-se que, no período pesquisado, cresceram as áreas voltadas para a produção de uvas de mesa. Em relação à sua inserção no mercado, verificou-se a necessidade de criação de uma forma de cooperação que permita aos produtores de uva agregar valor à sua produção. A ampliação do cultivo de uvas finas de mesa no município de Uraí é parte de um movimento de expansão da fruticultura em geral na região do Norte Pioneiro do Paraná, o qual está associado ao processo de reestruturação produtiva e à tentativa de viabilização de unidades familiares de produção agrícola.

Fica evidente que a diversidade de atividades é adotada nas propriedades visitadas como estratégia de permanência e reprodução social. A diversificação na unidade de produção acontece como estratégia para manter-se na terra, pois, caso uma das atividades desenvolvidas na propriedade não gere renda suficiente para o sustento da família, o produtor tem outras atividades para subsidiar a manutenção da mesma.

Assim, a reprodução das famílias pesquisadas só é possível porque a lógica desses produtores é a permanência na propriedade através do trabalho familiar e para isso há a constante busca por estratégias para não serem expropriados. As estratégias de produção diversificada na agricultura familiar surgem como nova alternativa para a permanência do produtor no campo. $\mathrm{O}$ reconhecimento de que nas cidades as dificuldades podem ser ainda maiores leva a grande maioria dos produtores a continuar no campo, já que, segundo eles, é a realização das atividades agropecuárias no campo "o que sabem e gostam de fazer". Outro elemento que justifica a vontade de permanecer no campo é o apego à propriedade familiar, que na maior parte dos casos foi recebida como herança e traz laços de parentescos.

As entrevistas demonstraram que o pequeno agricultor ainda quer se manter na propriedade. Uma das alegações é a afirmação de que é "só isso que ele sabe fazer", mas, 
quando se trata da permanência dos filhos no campo, ele reluta em dizer "que os mesmos têm outras oportunidades e perspectivas e devem buscar outra atividade no mercado de trabalho para que não fiquem com a dependência financeira, exclusivamente da atividade agrícola".

As colocações acima justificam a realização desta pesquisa, como uma contribuição para o entendimento dessas questões que revela o quanto é complexa e ao mesmo tempo particular.

\section{REFERÊNCIAS}

BUAINAIN, A. Márcio R, A.R., GUANZIROLI, C. Agricultura Familiar e o Novo Mundo Rural. Dossiê Sociologias, Porto Alegre, ano 5, $n^{\circ} 10$, jul/dez 2003, p. 312-347.

INSTITUTO BRASILEIRO DE GEOGRAFIA E ESTATÍSTICA. Censo Demográfico 1950-2000.

INSTITUTO BRASILEIRO DE GEOGRAFIA E ESTATÍSTICA. Produção Agrícola Municipal: Culturas Temporárias e Permanentes. V. 32. Brasil, 2005.

INCRA/FAO. Perfil da Agricultura Familiar no Brasil: dossiê estatístico. Brasília, 1996 Instituto Paranaense de Assistência Técnica e Extensão Rural. EMATER, Uraí-PR.

2009 - 2010.

LAMARCHE, H. (Coord.). A agricultura familiar: comparação internacional. Tomo I. Trad. TIJIWA, A. M. N. Campinas: Ed. Da UNICAMP, 1993.

MARTINS, J. de S. Os camponeses e a política no Brasil. Petrópolis: Vozes, 1983.

NEVES, D. P. Agricultura Familiar: quantos ancoradouros! In: FERNANDES, B. M.; MARQUES, M. I. M.; SUZUKI, J. C. (org.) Geografia Agrária: teoria e poder. 1ª ed. São Paulo: Expressão Popular, 2007.

OLIVEIRA, A. U. de, Agricultura camponesa no Brasil. 3. ed. São Paulo: Contexto, 1991 (Caminhos da Geografia).

Modo capitalista de produção e agricultura. São Paulo, Ática, 1995, 4a ed. 88p.

TAVARES DOS SANTOS, J. V. Colonos do Vinho. São Paulo, Hucitec, 1984.

URAÍ. BRASIL, Prefeitura do Município de Uraí. 1995.

Recebido em 01/07/2013

Aceito para publicação em 22/10/2013 